\title{
Karyomorphological Studies of Four Species of Japanese Scleria (Cyperaceae)
}

\author{
Okihito Yano and Takuji Hoshino* \\ Department of Mathematical and Environmental System Science, Graduate School of Informatics, \\ Okayama University of Science, Ridai-cho 1-1, Okayama-shi, Okayama 700-0005, Japan.
}

Received April 6, 2007; accepted June 16, 2007

\begin{abstract}
Summary Four species of Japanese Scleria were used for karyomorphological studies. Chromosome numbers of $S$. mikawana $(2 n=20)$ and S. levis $(2 n=48)$ were determined for the first time. Our finding of $2 n=30$ for $S$. parvula and $2 n=48$ for $S$. terrestris differs from those of previous studies. Two major groups were identified in the genus Scleria by karyomorphological data: (1) low chromosome numbers and $x=5$, (2) high chromosome numbers $(2 n=48)$. These karyomorphological data support the taxonomical treatment of 2 sections by Ohwi (1944). The high chromosome numbers may arise by polyploidy of low chromosome numbers because chromosome sizes were almost equal in both. Therefore, chromosomal evolution in the genus Scleria may be caused by polyploidy, rather than aneuploidy.
\end{abstract}

Key words Chromosome number, Cyperaceae, Diffuse centromeric chromosome, Polyploidy, Scleria.

Genus Scleria Bergius is distributed mainly in tropical and warm-temperate regions, and includes about 200-250 species (Tucker 1987, Goetghebeur 1998, Reznicek et al. 2002). In Japanese Scleria, Ohwi (1944) recognized 7 species and 2 varieties, and classified into 2 sections (Elatae and Tessellatae). Koyama (1961) reported 11 species and 1 forma in Asian Scleria, of which 8 species and 1 forma are distributed in Japan.

The chromosome numbers of the genus Scleria have been reported by Tanaka (1941), Patnaik and Rath (1983), and Nijalingappa and Leela Bai (1990). Tanaka (1941) reported $2 n=28$ for $S$. parvula (as $S$. tessellata), while Patnaik and Rath (1983) reported $2 n=112$ for S. terrestris. Nijalingappa and Leela Bai (1990) obtained the chromosome numbers of $2 n=10$ for S. pergracilis, $2 n=20$ for $S$. foliosa, and $2 n=100$ for $S$. lithosperma. However, there have been only 3 reports on cytological studies of genus Scleria. Accurate karyomorphological studies of the genus Scleria would contribute significantly to clarify relationships of the chromosome and taxonomical treatment in this genus. The purpose of this paper is to report the chromosome numbers and karyotypes of four species in the Japanese Scleria, and to discuss their relationships and chromosomal evolution.

\section{Materials and methods}

Karyomorphological observations were conducted on 4 species of Japanese Scleria. Voucher specimens and localities of the materials are listed in Table 1. Somatic chromosomes were observed in the meristematic cells of root tips. The root tips were pretreated in $2 \mathrm{mM} 8$-hydroxyquinoline solution for $1 \mathrm{~h}$ at $23^{\circ} \mathrm{C}$ and then $15 \mathrm{~h}$ at $4^{\circ} \mathrm{C}$. They were then fixed in a solution of acetic acid and ethylalcohol $(1: 3)$ for at least $16 \mathrm{~h}$ at $-20^{\circ} \mathrm{C}$ or for $1.5 \mathrm{~h}$ at $23^{\circ} \mathrm{C}$, stained using Feulgen's nuclear reaction, macerated in a mixture of $2 \%$ pectinase and $2 \%$ cellulase for $1 \mathrm{~h}$ at $37^{\circ} \mathrm{C}$, restained in a so-

\footnotetext{
*Corresponding author, e-mail: hoshino@big.ous.ac.jp
} 
lution of $1 \%$ aceto-orcein, and then squashed. Voucher specimens were deposited in the Herbarium of Okayama University of Science (OKAY).

\section{Results}

The chromosome numbers determined in this study are shown in Table 1. The chromosomes of the genus Scleria are thought to be polycentric, because primary constriction was not observed in any species. Chromosome numbers of $2 n=20$ for $S$. mikawana and $2 n=48$ for $S$. levis, were determined for the first time in this study (Fig. 1). New chromosome numbers were observed in 2 species, $2 n=30$ for $S$. parvula and $2 n=48$ for $S$. terrestris (Fig. 1, Table 1).

The genus Scleria can be classified into the following two major groups based on the karyotype analysis. The first group has low chromosome numbers, including species with $2 n=20$ and 30 , and has a basic chromosome number $x=5$. Somatic chromosomes of these species range from $1.1 \mu \mathrm{m}$ to $1.6 \mu \mathrm{m}$ in length (Fig. 1A, B). The second group has high chromosome numbers, including species with $2 n=48$, and their somatic chromosomes range from 0.7 to $1.3 \mu \mathrm{m}$ in length (Fig. $1 \mathrm{C}, \mathrm{D})$.

\section{Discussion}

Tanaka (1941) reported that Scleria parvula from Nagano Prefecture has $2 n=28$, while our results showed $2 n=30$ for $S$. parvula from Okayama Prefecture (Table 1). The $2 n=30$ of $S$. parvula may be an intraspecific aneuploid, which is thought to be common in Cyperaceae plants with diffuse centromeric chromosomes. Patnaik and Rath (1983) reported $S$. terrestris has $2 n=112$, while our results showed $2 n=48$ for $S$. terrestris from Okinawa Prefecture in Japan (Table 1). We observed a lower chromosome number in Japanese $S$. terrestris than the number reported by Patnaik and Rath (1983). More individuals should be examined for confirming the chromosomal evolution.

Japanese Scleria is classified into 2 sections, Elatae and Tessellatae, by Ohwi (1944). In his classification, the rhizomes, inflorescences, and ornament of achenes are considered the major character for distinguishing the section Elatae from the section Tessellatae. In section Elatae, the rhizomes are thick, partial inflorescences are large with many spikelets, and achenes are nearly smooth. However, in section Tessellatae, the rhizomes are absent, partial inflorescences are small with few spikelets, and achenes are reticulate. Scleria levis and S. terrestris belong to section Elatae, while S. parvula and S. mikawana belong to section Tessellatae. In this study, the species of the section Elatae had high chromosome numbers, $2 n=48$, while the section Tessellatae had low chromosome numbers, $2 n=20$ and 30 . Our karyomorphological results support taxonomical treatment of two sections by Ohwi (1944). Our results show also that the rhizomes, inflorescences, and ornament of achenes are important characters for separating these 2 sections.

Nijalingappa and Leela Bai (1990) recognized the following 2 major groups in the genus Scleria based on the chromosome observations; (1) ploidy series on the basic number $x=5(2 n=10,20$, and 100) and (2) ploidy series on the basic number $x=7(2 n=28$ and 112). They reported that polyploidy may have played an important role of the speciation in the genus Scleria. Our results suggest that the ancestor of section Tessellatae is postulated to have a basic chromosome number of $x=5$. High chromosome numbers of section Elatae $(2 n=48)$ might have arisen by polyploidy of low chromosome numbers because chromosome sizes were almost equal in both. Hoshino (1981) reported that when the chromosome number increases by agmatoploidy (fragmentation) in the genus Carex, both the lengths and widths of all chromosomes tend to become smaller. Yano and Hoshino $(2005,2006)$ reported that when the chromosome number increases by polyploidy or chromosome duplication in the genera Eleocharis and Schoenoplectus, both the lengths and widths of all chromosomes tend to become almost equal. Our karyomorphological data show the chromosomal evo- 
Table 1. Species, localities and voucher specimens, and chromosome numbers of four species in the genus Scleria collected from Japan. Vouchers are deposited in OKAY.

\begin{tabular}{|c|c|c|}
\hline Locality and Voucher specimen & Chromosome number $(2 n)$ & Previous report $(2 n)$ \\
\hline \multicolumn{3}{|l|}{ Scleria Berg. } \\
\hline \multicolumn{3}{|l|}{ S. mikawana Makino } \\
\hline Okayama Pref., Bizen; Hoshino et al. 21044 (OKAY) & 20 & \\
\hline \multicolumn{3}{|l|}{ S. parvula Steud. } \\
\hline Okayama Pref., Sohjya; Katayama 21024 (OKAY) & 30 & 28 (Tanaka 1941) \\
\hline \multicolumn{3}{|l|}{ S. levis Retz. } \\
\hline Okayama Pref., Bizen; Hoshino et al. 21029 (OKAY) & 48 & \\
\hline \multicolumn{3}{|l|}{ S. terrestris (L.) Fassett } \\
\hline Okinawa Pref., Yaeyama; Kobayashi 20575 (OKAY) & 48 & 112 (Patnaik and Rath 1983) \\
\hline
\end{tabular}
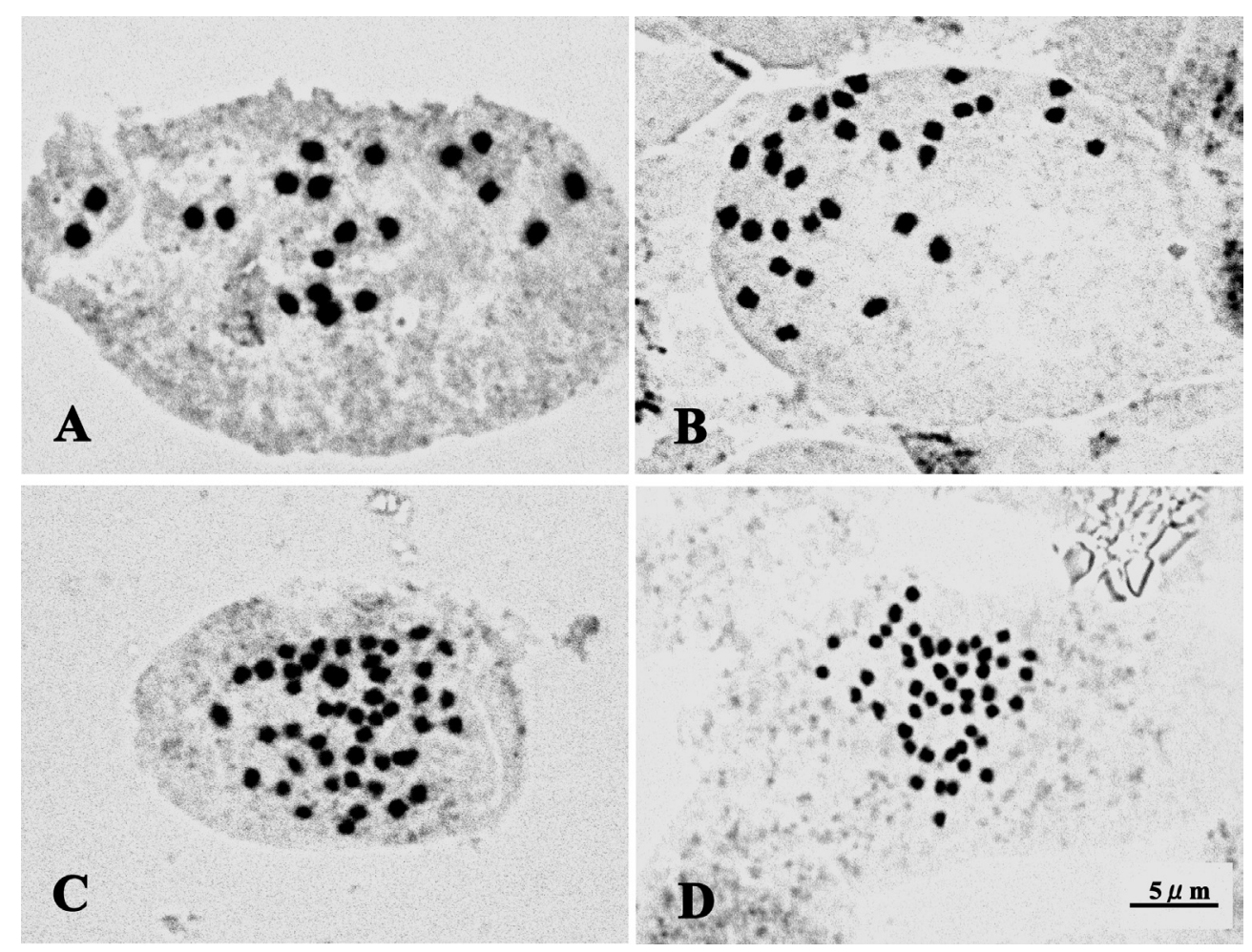

Fig. 1. Photomicrographs of somatic metaphase chromosomes of four species in the genus Scleria. A. S. mikawana $(2 n=20)$. B. S. parvula $(2 n=30)$. C. S. levis $(2 n=48)$. D. S. terrestris $(2 n=48)$.

lution in the genus Scleria with diffuse centromeric chromosomes may have been caused by polyploidy rather than aneuploidy. Future studies should include examining more samples and phylogeny based on DNA sequences data in order to understand the phylogenetics and chromosome evolution of the genus Scleria. 


\section{Acknowledgments}

The authors thank Messrs Hisashi Katayama, Junichi Fujii, and Shiro Kobayashi for their great help in collecting plant materials.

\section{References}

Goetghebeur, P. 1998. Cyperaceae. In: Kubitzki, K. (ed.). The Families and Genera of Vascular Plants 4. Flowering Plants, Monocotyledons: Alismatanae and Commelinanae (except Gramineae). Springer, Berlin. pp. 141-190.

Hoshino, T. 1981. Karyomorphological and cytogenetical studies on aneuploidy in Carex. J. Sci. Hiroshima Univ., Ser. B., Div. 2, Bot. 17: 155-238.

Koyama, T. 1961. Classification of the family Cyperaceae I. J. Fac. Sci. Univ. Tokyo, Sect. 3, Bot. 8: 134-139.

Nijalingappa, B. H. M. and Leela Bai, D. 1990. Cytological studies in Scleria. J. Cytol. Genet. 25: 133-136.

Ohwi, J. 1944. Cyperaceae Japonicae. II. A synopsis of the Rhynchosporoideae and Scirpoideae of Japan, including the Kuriles, Saghalien, Korea and Formosa. Mem. Coll. Sci. Kyoto Imp. Univ. Ser. B, Biol. 18: 4-10.

Patnaik, S. N. and Rath, S. P. 1983. Chromosomal evolution in Cyperaceae. In: Sinha, R. P. and Sinha, U. (eds.). Current Approaches in Cytogenetics. Spectrum Publ. House, Patna-New Delhi. pp. 123-133.

Reznicek, A. A., Fairey III, J. E. and Whittemore, A. T. 2002. Scleria. In: Flora of North America editorial committee (ed.). Flora of North America, Vol. 23. Magnoliophyta: Commelinidae (in part) Cyperaceae. Oxford University Press, New York. pp. 242-251.

Tanaka, N. 1941. Chromosome studies in Cyperaceae, XII. Pollen development in five genera, with special reference to Rhyncospora. Bot. Mag. (Tokyo) 55: 55-65.

Tucker, G. C. 1987. The genera of Cyperaceae in the southeastern United States. J. Arnold Arbor. 68: 420-422.

Yano, O. and Hoshino, T. 2005. Molecular phylogeny and chromosomal evolution of Japanese Schoenoplectus (Cyperaceae), based on ITS and ETS 1f sequences. Acta Phytotax. Geobot. 56: 177-189.

— and - 2006. Cytological studies of aneuploidy in Eleocharis kamtschatica (Cyperaceae). Cytologia 71: 141-147. 